\title{
Comportamento da Gasolina com Etanol (E-20) e da Gasolina Pura Após a Simulação de um Vazamento em Colunas de Laboratório
}

\author{
Sílvia Maria Ferreira' (silvia@hidroplan.com.br), Everton de Oliveira', Uriel Duarte² \\ 'Hidrogeologia e Planejamento Ambiental - HIDROPLAN \\ Av. São Camilo 476, CEP 06709-150, Cotia, SP, BRA \\ 2Departamento de Geologia Sedimentar e Ambiental - Instituto de Geociências - USP, São Paulo, SP, BRA
}

Palavras-chave: gasolina, etanol, hidrocarbonetos.

\section{RESUMO}

A gasolina que é comercializada no Brasil sofre a adição de etanol em frações que podem variar de 20 a $24 \%$. Este aditivo oxigenado aumenta a octanagem e reduz a emissão de monóxido de carbono para a atmosfera. Vazamentos em tanques de armazenamento subterrâneos e linhas de distribuição podem causar a contaminação do solo e das águas subterrâneas, sendo que a característica co-solvente do etanol altera o comportamento da gasolina em subsuperfície, portanto, esta pesquisa teve como objetivo estudar a relação existente entre a espessura encontrada nos poços de monitoramento e no meio poroso, tanto para gasolina pura quanto para a E-20 (80\% de gasolina e 20\% de etanol), após a simulação de um vazamento em subsuperfície, utilizando colunas de areia em laboratório, visto que esta relação é de extrema importância para o cálculo preciso do volume do contaminante a ser bombeado, no caso de vazamentos de combustível. Duas colunas foram confeccionadas utilizando-se dois tubos de acrílico transparente com $100 \mathrm{~cm}$ de comprimento e $23 \mathrm{~cm}$ de diâmetro interno que foram fixados a uma base de acrílico transparente com $0,60 \mathrm{~cm}$ de espessura. As colunas foram preenchidas com areia de granulometria muito fina $(0,088 \mathrm{~mm})$. Os resultados obtidos mostraram que a espessura aparente da gasolina pura foi 2,6 vezes superior à espessura real da fase livre e a espessura aparente da E-20 foi 0,6 vezes superior à espessura real da fase livre para o meio poroso avaliado. A tensão interfacial da E-20 foi $67 \%$ inferior à tensão interfacial da gasolina pura, possibilitando que uma quantidade maior de poros fosse acessada, refletindo em valores de saturação total 54\% superiores ao da gasolina pura.

Keywords: gasoline, ethanol, hydrocarbons.

\begin{abstract}
Commercial gasolines sold in Brazil are added ethanol from 20 to $24 \%$ by volume. This oxygenated additive raises the octane level and reduces carbon monoxide emissions to the atmosphere. Underground storage tanks and gasoline lines are a major potential problem for soil and groundwater contamination. Since ethanol has cosolvent properties that alter the behavior of phase distribution in subsurface, this study compares the existing relationship between apparent and real thicknesses of free phase gasoline and E-20 (80\% gasoline and 20\% ethanol by volume) found respectively in monitoring wells and porous medium material used in two column experiments. Two cylindrical plexiglass columns were used $(100 \mathrm{~cm}$ long and $23 \mathrm{~cm}$ in internal diameter). The bottom ends were capped using plexiglass plate $0.60 \mathrm{~cm}$ thick. A spout-like connection of PVC was fitted near the base of each column as an inlet/outlet. One well screen $(100 \mathrm{~cm}$ long and $3,5 \mathrm{~cm}$ in internal diameter) in white PVC was cut in half lengthwise and attached to the inside walls of columns to be used as monitoring wells. The columns were then filled with $0,088 \mathrm{~mm}$ grain size sand (very fine). The apparent thickness of pure gasoline was 2.6 times thicker than the actual thickness in the aquifer while it was only 0.6 thicker for E-20. The interfacial tension of E-20 is $67 \%$ lower than that of the pure gasoline, allowing a larger quantity of pores to be accessed, which was reflected in oil saturation $54 \%$ greater than that of pure gasoline.
\end{abstract}




\section{INTRODUÇÃO}

O Brasil possui mais de 29.000 postos de distribuição de combustíveis, sendo que no Estado de São Paulo estão concentrados mais de 8.400 postos, dos quais 2.400 se localizam na Região Metropolitana de São Paulo (CETESB, 2002).

Levantamentos realizados por agências ambientais indicam que as áreas onde estão localizados esses postos de serviços são freqüentemente atingidas por vazamentos oriundos de tanques de armazenamento subterrâneos (TAS), que podem causar a contaminação do solo e das águas subterrâneas, além de contribuírem para o risco de explosões e incêndios.

Segundo dados da Companhia de Tecnologia de Saneamento Ambiental - CETESB (2001), dos acidentes ambientais que ocorreram em postos de serviços no Estado de São Paulo e notificados em 2000, 14\% foram nas cidades do interior, 22\% nos municípios da Região Metropolitana de São Paulo e 64\% no Município de São Paulo, sendo que os TAS foram responsáveis por $42 \%$ desses acidentes e a gasolina foi o produto com maior vazamento.

A gasolina que é comercializada no Brasil sofre a adição de álcool etílico anidro, conhecido comercialmente como etanol, em frações que podem variar de 20 a $24 \%$. O uso desse composto oxigenado adicionado à gasolina serve para aumentar a octanagem e reduzir a emissão de monóxido de carbono para a atmosfera. Nos EUA, por exemplo, desde que o uso de MTBE (éter metil terc-butílico) como aditivo foi vetado, devido ao fato de comprometer a qualidade da água subterrânea, o etanol foi escolhido como a principal alternativa.

Muitos autores como De Pastrovich et al. (1979), Hall et al. (1984), Schiegg (1985), Farr et al. (1990), Lenhard e Parker (1990), Ballestero et al. (1994), Pereira (2000) e Ferreira (2003) já tentaram desenvolver correlações para que a espessura da fase livre no meio poroso (espessura real) fosse estimada a partir de medições feitas em poços de monitoramento (espessura aparente), permitindo a estimativa do volume da fase livre para sua posterior remediação.

Esta pesquisa teve como objetivo principal verificar e comparar a relação existente entre a espessura encontrada nos poços de monitoramento e no meio poroso, tanto para gasolina pura quanto para a gasolina com $20 \%$ de etanol (E-20), após a simulação de um vazamento em subsuperfície, utilizando colunas de areia em laboratório. Além de determinar a tensão interfacial da gasolina pura e da E-20 e observar a evolução do efeito de co-solvência do etanol tanto na fase aquosa quanto na fase gasolina.

\section{COMPORTAMENTO DOS HIDROCARBONETOS}

Nos últimos anos, houve um número significativo de ocorrências de vazamentos de combustíveis, principalmente em tanques de armazenamento subterrâneos (TAS), localizados em postos de serviços, sendo que a gasolina foi o produto com maior vazamento.

Muitos postos de serviços possuem tanques muito antigos, que estão sujeitos à corrosão, e vazamentos ocorrem geralmente em vazões reduzidas, que só são percebidas pelo gerente do posto quando há uma perda considerável de combustível. O aumento progressivo desses vazamentos, principalmente no Estado de São Paulo, reflete o envelhecimento dos TAS instalados, cuja tendência é se agravar futuramente, caso a situação não se altere.

Essa situação tende a mudar em função da Resolução 273/2000, do Conselho Nacional do Meio Ambiente CONAMA (CETESB, 2001) que exige dos estabelecimentos que armazenam e comercializam combustíveis no país o licenciamento pelo órgão ambiental competente, a CETESB, no caso do Estado de São Paulo. Deste modo, os postos de serviços terão que adequar equipamentos e sistemas para o aumento da segurança no armazenamento de combustíveis visando uma redução nos acidentes com vazamentos. Esta medida beneficia a população, pois a maioria desses estabelecimentos localiza-se em áreas densamente povoadas.

\section{Migração dos hidrocarbonetos}

Segundo a relação apresentada pela Groundwater Technology Inc. (Wilson e Brown, 1989), quando ocorre um vazamento de gasolina a partir de um tanque de armazenamento subterrâneo, $62 \%$ do volume total de contaminante corresponde à fase livre imiscível, 33\% corresponde à fase residual e apenas $5 \%$ corresponde à fase dissolvida. Entretanto, a distribuição em termos de volume contaminado apresenta apenas $1 \%$ à fase livre imiscível, $20 \%$ à fase residual e 79\% à fase dissolvida.

Por ser a gasolina um produto menos denso que a água, é classificada como LNAPL (light non-aqueous phase liquids), isto é, fase líquida imiscível leve ou menos densa que a água.

A Figura 1 ilustra o comportamento de um vazamento de LNAPL típico, sendo que o contaminante pode estar na subsuperfície em cinco fases distintas: livre, residual, dissolvida, vapor e adsorvida (Oliveira, 1998). Quando o produto migra verticalmente em direção ao aqüífero e aloja-se sobre a franja capilar, forma-se um reservatório, caracterizando a fase livre. 


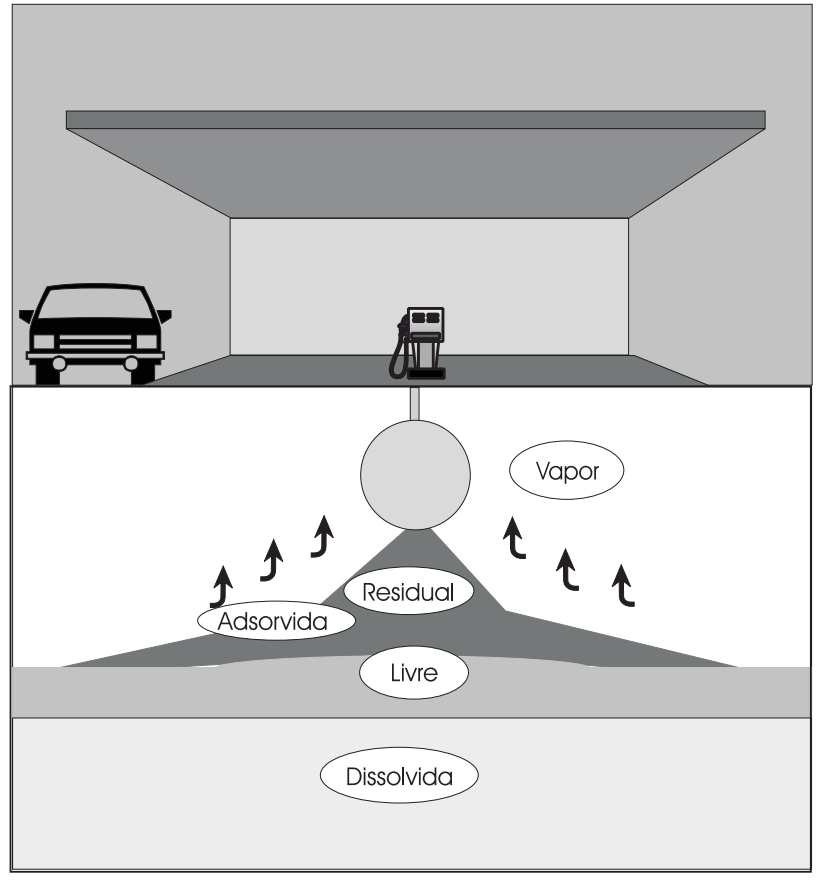

Figura 1. Fases distintas de LNAPL após um vazamento em um aqüífero.

A fase residual ocorre quando parte do produto que percola fica retido no meio poroso sob a forma de glóbulos ou grupo de glóbulos desconectados, esta fase pode eventualmente ser remobilizada, retornando à fase livre e vice-versa.

Já a fase dissolvida é formada pelo produto dissolvido na água subterrânea e é considerada uma das mais importantes, pois é a fonte mais volumosa de uma contaminação. No caso da gasolina, que tem uma variedade de compostos orgânicos com diferentes solubilidades, os compostos mais solúveis irão se dissolver mais rapidamente deixando para trás os menos solúveis. Este processo afeta a concentração do composto na fase aquosa, que diminuirá proporcionalmente com a diminuição da sua fração molar na mistura. A solubilidade dos componentes que formam a gasolina também é fortemente afetada pela composição da mistura e tende a ser menor que a solubilidade do componente puro.

A fase adsorvida é formada quando parte do produto fica adsorvido na matéria orgânica presente no aqüífero. Em um solo seco ou com uma concentração baixa de umidade, a quantidade adsorvida está diretamente relacionada à área da superfície das partículas do solo e à quantidade de matéria orgânica.
Os componentes mais voláteis resultam principalmente da volatilização dos hidrocarbonetos da fase residual presente na zona não saturada, ou ainda de hidrocarbonetos da fase adsorvida e, em menor escala, a partir de hidrocarbonetos da fase livre ou dissolvida.

\section{Efeito de co-solvência do etanol}

Enquanto a gasolina pura é quase imiscível na água, o etanol é completamente miscível na gasolina e na água em todas as concentrações. Quando o etanol está presente na gasolina e na água, particiona-se preferencialmente dentro da fase aquosa, aumentando a solubilidade de BTEX na água e reduzindo a tensão interfacial da gasolina-água. O sistema final seria composto de uma fase de água com álcool e alguma gasolina dissolvida, e uma fase de gasolina com álcool e um pouco de água dissolvida. Com uma proporção suficientemente alta de etanol em um sistema, a gasolina e a água tornam-se completamente miscíveis e uma fase única será desenvolvida.

Este comportamento complexo de particionamento de etanol dentro das fases da água e da gasolina é descrito pelo diagrama pseudoternário (Figura 2), que permite o agrupamento de componentes múltiplos como um pseudocomponente, como é o caso da gasolina. Cada ápice do triângulo representa $100 \%$ da concentração de um componente simples (ou pseudocomponente) gasolina, água e etanol. A região cinza indica o limite das frações da água, gasolina e etanol onde os três componentes existem como duas fases separadas, enquanto a região branca indica o limite da composição onde esses componentes existem como uma fase simples. A curva separando as duas regiões é chamada de curva binodal. Acima dessa curva a gasolina, o etanol e a água existem como uma fase única em todas as combinações relativas de água e gasolina, desde que o etanol presente no sistema exceda $70 \%$ em peso.

As linhas de equilíbrio (tie lines) que se encontram na região de duas fases unem os segmentos ricos em água e ricos em gasolina da curva binodal. Essas linhas indicam as composições em equilíbrio das duas fases, e os pontos conectados por elas definem a composição da fase rica em água (sobre o lado esquerdo da região de duas fases) e a fase rica em gasolina (sobre o lado direito da região de duas fases). O particionamento preferencial do etanol dentro da água é indicado pela inclinação das linhas de equilíbrio para a direita, que tendem para um ponto chamado de ponto crítico (plait point), onde a composição das duas fases é a mesma. 


\section{Espessura de um produto móvel}

Muitos pesquisadores têm tentado desenvolver métodos para explicar como pequenas quantidades de hidrocarbonetos móveis podem levar a espessuras exageradas de hidrocarbonetos medidas em poços. Hampton e Miller (1988) e Ballestero et al. (1994) fizeram revisões a respeito dos métodos usados para estimar a espessura do produto livre no solo adjacente, a partir de medições feitas nos poços de monitoramento. Essas estimativas podem ser divididas em dois tipos. O primeiro, fundamentado na derivação de correlações empíricas, baseadas nas diferenças de densidade do fluido, no tamanho do grão do meio poroso, ou na espessura da franja capilar e, o segundo, fundamentado no desenvolvimento de modelos baseados nas curvas de pressão capilar-saturação. Apesar da atenção que tem sido dada para o desenvolvimento de correlação entre a espessura do produto livre medida nos poços e o volume de produto livre no solo, nenhum desses métodos disponíveis têm sido particularmente confiáveis quando testados ou em campo (Durnford et al., 1991; Huntley et al., $1992 \mathrm{e}$ Ballestero et al., 1994) ou em laboratório (Hampton e Miller, 1988). Segundo Durnford et al. (1991), as limitações dos métodos desenvolvidos para relatar essas correlações são:

1. espessuras do produto livre observadas nos poços de monitoramento mudam com as flutuações do nível d'água. Cada espessura diferente que é medida do produto livre no poço resulta em um cálculo diferente do produto livre no aqǘf́ero, mesmo se o volume real de produto livre não tiver mudado;

2. nenhum dos métodos para estimação contam com os hidrocarbonetos residuais e trapeados - uma porção destas frações pode retornar à fração de produto livre quando o nível d'água se move;

3. métodos que são baseados nas medições das propriedades do solo e do fluido requerem medições (curvas de pressão capilar versus saturação) que são difíceis de se obter em campo, e medições derivadas no laboratório que não podem representar precisamente as condições do campo;

4. nenhum dos métodos conta com a variabilidade espacial (heterogeneidade) dos parâmetros do aqüífero. O movimento do produto livre é muito dependente das heterogeneidades do aquífero, que são raramente representadas adequadamente pelas propriedades médias.
Apesar das deficiências destes métodos para estimar o volume, eles são comumente usados na prática.

Uma representação esquemática do efeito da flutuação do nível d'água subterrânea na espessura da lâmina de fase livre de um LNAPL, após o vazamento ter cessado, é mostrado na Figura 3.

Na Figura 3A, o nível d'água teve uma variação ascendente, acima do nível original, e quantidades consideráveis de produto presente em fase livre foram trapeadas abaixo do nível d'água passando para a fase residual, causando a diminuição da espessura da fase livre. Este fato ocorre devido ao deslocamento da porção inferior da lâmina de fase livre, pois o produto nesta fase vai sendo levado para cima pelo movimento ascendente do nível d'água e o ar presente vai sendo gradativamente eliminado (processo de embebição).

Na Figura 3B, ocorre uma variação descendente do nível d'água, e parte do produto residual que foi trapeado abaixo do nível d'água torna-se móvel e, conseqüentemente, uma lâmina de fase livre mais espessa é formada. Novas variações do nível d'água podem fazer com que este fenômeno se repita outras vezes, remobilizando e imobilizando o produto puro (passagem de fase residual para fase livre e vice-versa).

\section{Estudos Realizados com Colunas em Laboratório}

Para Lal et al. (1970), uma situação de vazamento de NAPL que ocorre em campo pode ser reproduzida em laboratório, utilizando-se uma coluna cilíndrica preenchida com solo. Segundo os autores, parâmetros como densidade e distribuição granulométrica são importantes para a definição apropriada do diâmetro da coluna e, após a realização de vários testes com diferentes diâmetros de 


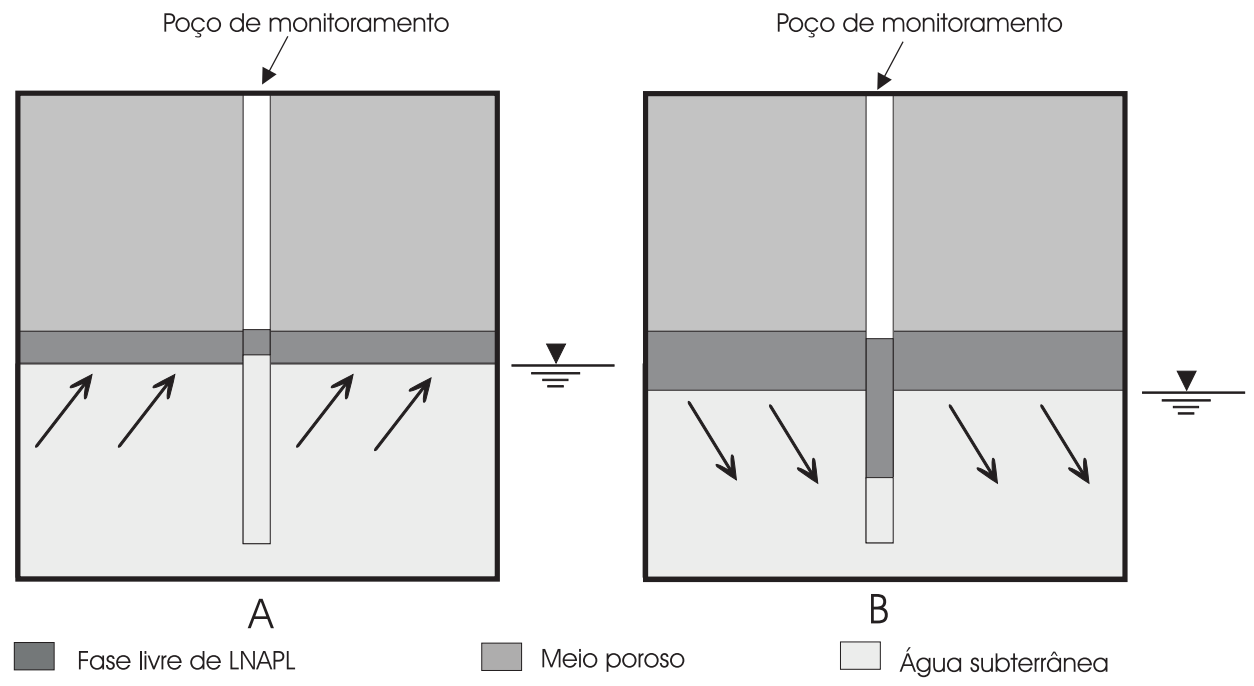

Figura 3. Representação esquemática do efeito da flutuação do nível d'água subterrânea na espessura da lâmina de fase livre de um LNAPL (adaptado de Kemblowski e Chiang, 1990).

colunas e com granulometrias variadas, estimaram em $10 \mathrm{~cm}$ o diâmetro mínimo da coluna, como medida mais viável para a verificação das relações de campo em laboratório.

Segundo Schiegg e McBride (1987), é necessário que a coluna tenha um diâmetro mínimo de $15 \mathrm{~cm}$, para materiais com granulometria inferior a $0,35 \mathrm{~mm}$, para que não haja migração preferencial do fluido nas paredes internas da coluna, ao invés de migração para o meio poroso.

Abdul et al. (1989), utilizaram uma coluna de acrílico em laboratório para verificar as limitações dos poços de monitoramento na detecção e quantificação de derivados de petróleo em solos e aqǘf́eros. A coluna de acrílico utilizada tinha $113,5 \mathrm{~cm}$ de altura e $10,8 \mathrm{~cm}$ de diâmetro interno, e possuía sete tensiômetros ajustados à sua parede. Esta coluna foi preenchida com areia muito fina a fina $(0,125$ a $0,250 \mathrm{~mm}$ ), sendo que o contaminante utilizado foi o óleo diesel. Os resultados experimentais mostraram que após o desenvolvimento da fase livre e da entrada de óleo no poço de monitoramento, a relação entre a espessura do óleo no poço de monitoramento e no meio poroso aumentou, enquanto os valores da fase livre no meio poroso permaneceram baixos. Segundo os autores, quando o nível d'água é estabelecido, é necessário que o registro utilizado para a entrada de água no sistema seja fechado, pois em experimentos sob condições de queda do nível d'água, o NAPL poderia fluir preferencialmente através da coluna mais rápido que para o poço de monitoramento.

Segundo Abdul (1988) e Adams e Hampton (1992), as dimensões escolhidas para a coluna e para o poço, devem obedecer a proporção de volume entre os tubos de 5:1. Estas medidas foram adotadas pelos autores, com o objetivo de propiciar a migração vertical do fluido e inibir seu transporte horizontal a longa distância.

Simmons et al. (1992), estudaram a infiltração de líquidos orgânicos no meio poroso não saturado, utilizando uma caixa acrílica preenchida com areia. Já Waddill e Parker (1997), utilizaram um tanque de aço preenchido com areia, para estudarem a recuperação de LNAPL no meio poroso.

Oliveira et al. (1998) simularam o efeito das variações sazonais do nível d'água utilizando colunas de PVC com $100 \mathrm{~cm}$ de comprimento e $30,48 \mathrm{~cm}$ de diâmetro interno, as quais foram preenchidas com amostras não deformadas de areia inconsolidada, e determinaram os valores de saturação da gasolina pura e da E-20 através de TDR (Time Domain Reflectometry). Segundo os autores, após o rebaixamento do nível d'água, onde o fluido molhante (água) é deslocado pelo não-molhante (gasolina), os valores máximos da saturação de gasolina foram mais elevados para a E-20 (85\%) quando comparados com a gasolina pura (78\%).

Pereira (2000) simulou um vazamento de gasolina sobre a franja capilar, utilizando duas colunas de acrílico transparente com $100 \mathrm{~cm}$ de comprimento e $23 \mathrm{~cm}$ de diâmetro interno, que foram preenchidas com micro esferas de vidro com $0,850 \mathrm{~mm}$ de diâmetro. Segundo a autora, a observação do comportamento da gasolina pura e da gasolina com etanol (E-24), foi realizada com sucesso. 
A realização desses diversos experimentos em laboratório, utilizando-se líquidos orgânicos diferentes, mostra que é viável a execução de experimentos em laboratório, com o objetivo de reproduzir situações de campo.

\section{MATERIAIS E MÉTODOS}

Para avaliar o comportamento da gasolina pura e da gasolina com etanol (E-20), após um vazamento em subsuperfície, foi desenvolvido um experimento em laboratório com a finalidade de reproduzir as características de um aquíffero e, desta forma, simular o vazamento destes combustíveis em laboratório.

Duas colunas foram confeccionadas na Oficina de Manutenção e Confecção de Equipamentos para Solo do Instituto de Geociências - IGc, utilizando-se dois tubos de acrílico transparente com $100 \mathrm{~cm}$ de comprimento, $23 \mathrm{~cm}$ de diâmetro interno e $0,30 \mathrm{~cm}$ de espessura.

Foi instalado um registro de PVC na parte inferior de cada tubo, com um anel de vedação constituído por viton, material escolhido por ser resistente à gasolina. Em seguida, cada tubo foi fixado a uma base de acrílico transparente com 0,60 cm de espessura, para ser preenchido com areia e reproduzir as zonas saturada e não saturada do aqüífero.

Um tubo de PVC branco com $100 \mathrm{~cm}$ de comprimento e $3,50 \mathrm{~cm}$ de diâmetro interno, com ranhuras horizontais de $0,10 \mathrm{~cm}$ de largura, foi cortado longitudinalmente e depois foi revestido com uma tela de aço inox com abertura de $0,038 \mathrm{~cm}$, com a finalidade de evitar a passagem de silte e

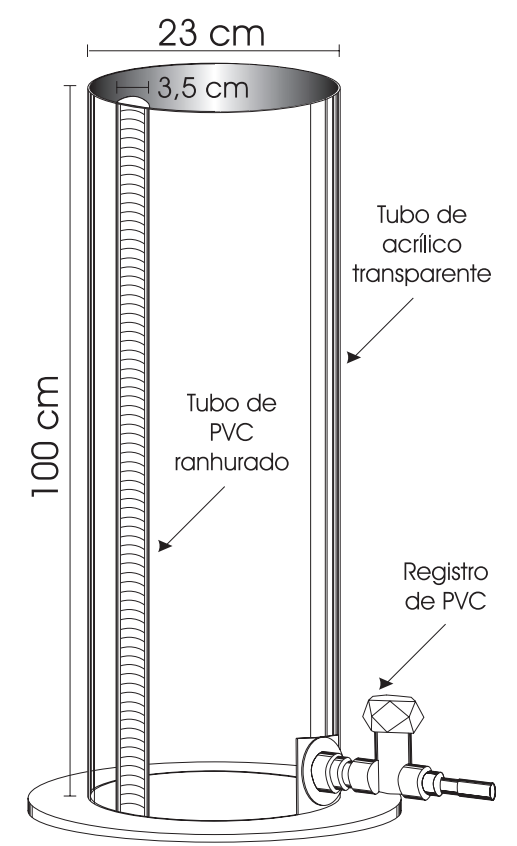

Figura 4. Esquema mostrando os detalhes de construção da coluna. areia muito fina. Cada metade foi fixada nas paredes dos tubos de acrílico, com o auxílio de Araldite Hobby, para representar o poço de monitoramento (Figura 4).

A areia usada para representar o meio poroso no experimento foi coletada em uma área da cidade de Bertioga (SP) e, depois de seca, foi peneirada para a desagregação dos grãos. As colunas foram preenchidas simultaneamente, com a ajuda de um tubo de PVC preto em forma de T, o qual foi ajustado ao poço de monitoramento e à parede oposta da coluna, com uma abertura na parte central, por onde a areia escoou.

Ambas colunas foram conectadas a um recipiente graduado de $20 \mathrm{~L}$ de capacidade, posicionados a $1 \mathrm{~m}$ de altura, através do registro e de mangueiras de silicone com $0,08 \mathrm{~cm}$ de diâmetro interno. Para o controle do fluxo d'água, utilizou-se uma torneira reta de duas vias e uma presilha (Foto 1).

A gasolina pura e a gasolina com $20 \%$ de etanol foram coloridas de vermelho, com o auxílio do corante líquido Sudan 462, com a finalidade de contrastar com a água e a areia do sistema. Em seguida, foram colocadas em duas provetas graduadas de $1000 \mathrm{~mL}$, as quais foram fixadas em duas hastes de aço e colocadas sobre as colunas.

A gasolina isenta de álcool é denominada de Gasolina Comum Tipo A e a gasolina com álcool é denominada de Gasolina Comum Tipo C. Neste trabalho, particularmente, a gasolina isenta de álcool será chamada de gasolina pura, e a gasolina que contém $20 \pm 1 \%$ de álcool etílico anidro será chamada de gasolina com etanol ou E-20.

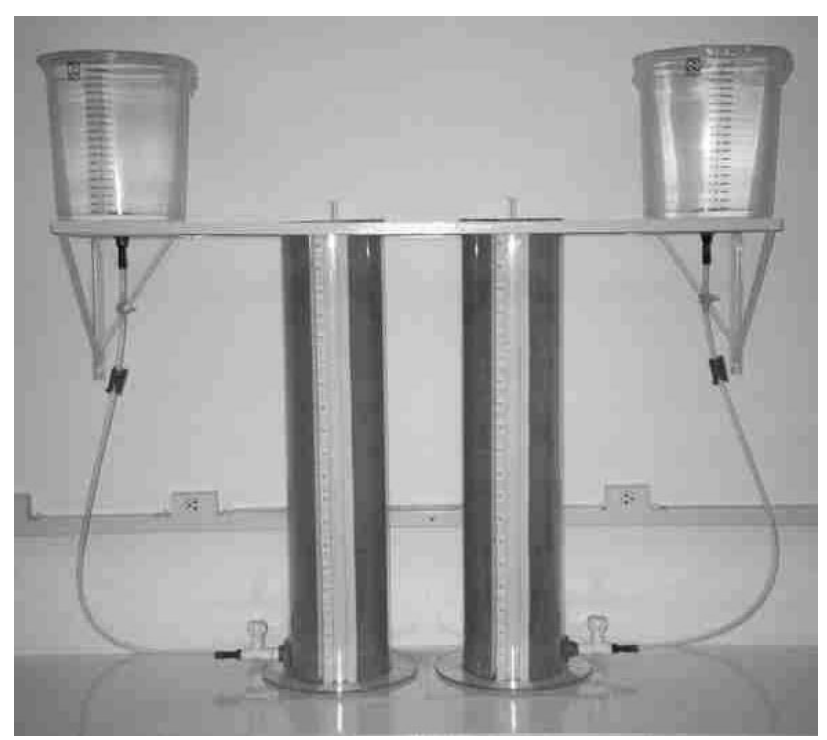

Foto 1. Colunas 1 (esquerda) e 2 (direita) montadas com os acessórios. 


\section{RESULTADOS E DISCUSSÕES}

Após a saturação das duas colunas com água, os recipientes foram colocados na altura de $50 \mathrm{~cm}$ para que a água entrasse em equilíbrio e, desta forma, o nível d'água se estabilizasse aproximadamente nesse valor, formando a franja capilar e também o teor de umidade acima desta franja, com o objetivo de reproduzir a umidade do solo.

Após 48 horas, o nível d'água na Coluna 1 se estabilizou na altura de 48,50 cm e na Coluna $2 \mathrm{em} 48,70 \mathrm{~cm}$, a partir da base das colunas. A franja capilar da Coluna 1 apresentou espessura variando entre 11,5 e 19,5 cm, e a franja capilar da Coluna 2 apresentou espessura variando entre 14,5 e $19 \mathrm{~cm}$, sendo que a elevação do nível d'água pôde ser visualizada através dos poços de monitoramento, e o avanço da água no meio poroso, através das paredes transparentes das colunas (Foto 2).

A variação encontrada na espessura da franja capilar das colunas se deve à variação granulométrica da areia que foi utilizada para o preenchimento das colunas, responsável por uma variedade de tamanhos de gargantas de poros, resultando em uma distribuição variável da saturação da água e, conseqüentemente, uma franja capilar com a superfície irregular.

Após as duas colunas estarem com o nível d'água estabilizado, a gasolina pura foi injetada sobre a franja capilar da Coluna 1, e a gasolina com $20 \%$ de etanol (E-20) foi injetada sobre a franja capilar da Coluna 2, respectivamente, com uma vazão média de $0,02 \mathrm{~cm}^{3} / \mathrm{s}$.

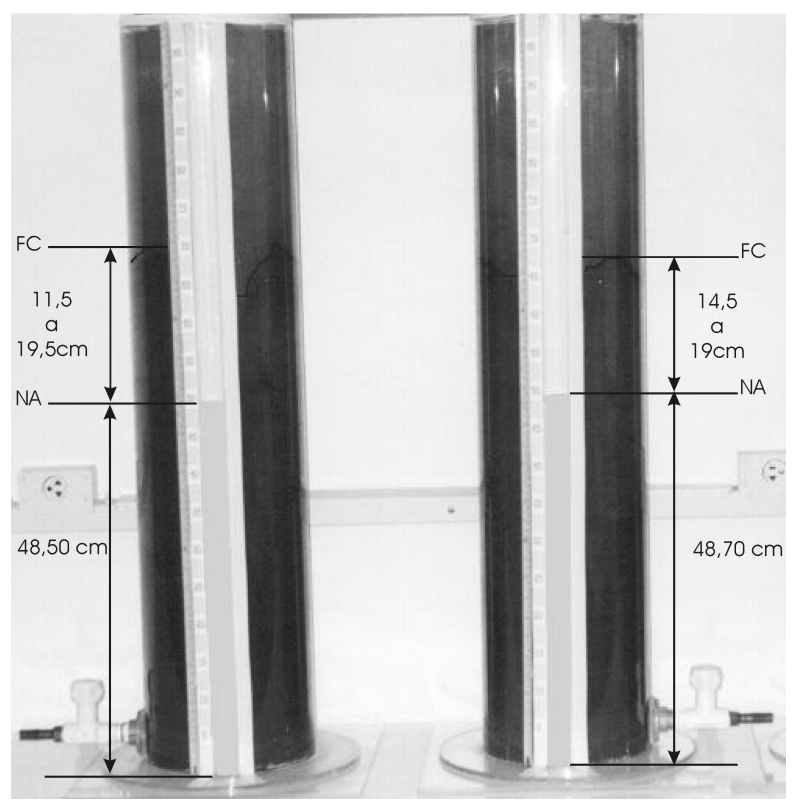

Foto 2. Colunas 1 (esquerda) e 2 (direita) após a saturação e o nível d'água estabilizado. FC - franja capilar. NA - nível d'água.
No Gráfico 1, observa-se a variação da espessura da gasolina pura no meio poroso e no poço de monitoramento na Coluna 1 , em função do tempo.

Pode ser observado através do Gráfico 1 que as espessuras da gasolina pura, tanto no meio poroso quanto no poço de monitoramento, variaram durante todo o experimento, resultando em uma relação entre ambas que variou entre 1,5 e 6,8 , sendo que no final do experimento esta relação permaneceu constante em 2,6.

Em seu trajeto de drenagem, a gasolina pura (fluido não molhante) invadiu primeiro os poros com diâmetros maiores, mais fáceis de serem acessados, por apresentarem valores mais baixos de pressão capilar, já que esta é inversamente proporcional ao raio dos poros. Em contato com a água, uma pequena porcentagem dos compostos BTEX, que são os mais solúveis da gasolina pura, devem ter se dissolvido.

No Gráfico 2, observa-se a variação da espessura da gasolina com etanol (E-20) no meio poroso e no poço de monitoramento na Coluna 2, em função do tempo.

A relação obtida através da variação da espessura da E-20, tanto no meio poroso quanto no poço de monitoramento, foi baseada no que foi visto através do experimento e, embora a fase livre tenha penetrado na franja capilar original da água, provavelmente desde o início da injeção, os cálculos levaram em consideração o que foi observado, sendo que a relação variou entre 0,6 e 1,3 com um valor médio de 0,8 . No final do experimento esta relação permaneceu em 0,6 .

Este experimento mostra claramente que há uma diferença muito grande entre o comportamento da gasolina pura e da gasolina com $20 \%$ de etanol (E-20).

Enquanto a gasolina pura apresenta uma espessura de $5,7 \mathrm{~cm}$ em 6 horas e 30 minutos, a E-20 não migra para o poço de monitoramento da Coluna 2, mas o nível d'água aumenta para 75,50 cm (Foto 3).

A Foto 4 mostra que a E-20 conseguiu migrar para o poço de monitoramento da Coluna 2, chegando a atingir a espessura máxima de $34,80 \mathrm{~cm}$, e uma zona de transição de $6,3 \mathrm{~cm}$, após 286 horas desde o início da primeira injeção, enquanto a gasolina pura apresentava $44,10 \mathrm{~cm}$ de espessura no poço de monitoramento da Coluna 1.

$\mathrm{O}$ experimento realizado neste trabalho mostrou que o comportamento em subsuperfície da gasolina com $20 \%$ de etanol (E-20) é mais complexo do que o da gasolina pura, pois, enquanto um volume de $675 \mathrm{~mL}$ de gasolina pura foi suficiente para formar uma espessura máxima de $52 \mathrm{~cm}$ de fase livre no poço de monitoramento da Coluna 1 , foram utilizados $2.780 \mathrm{~mL}$ de E-20 para atingir uma espessura máxima de $34,80 \mathrm{~cm}$ de fase livre no poço de monitoramento da Coluna 2. Além dessa quantidade de gasolina ser quatro vezes maior, o tempo necessário para que a mesma penetrasse no poço de monitoramento foi 33 vezes maior. 


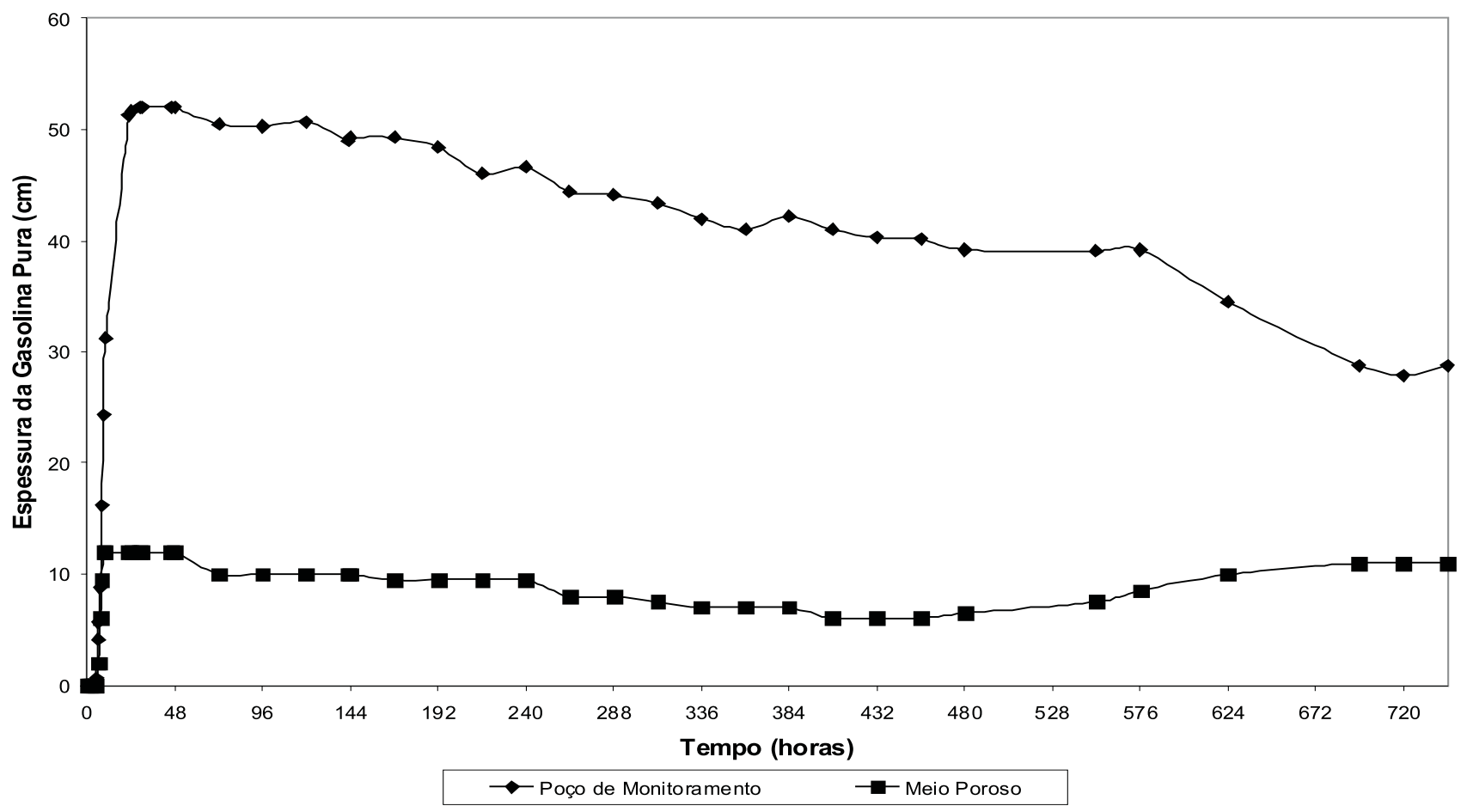

Gráfico 1. Variação da espessura da gasolina pura no meio poroso e no poço de monitoramento.

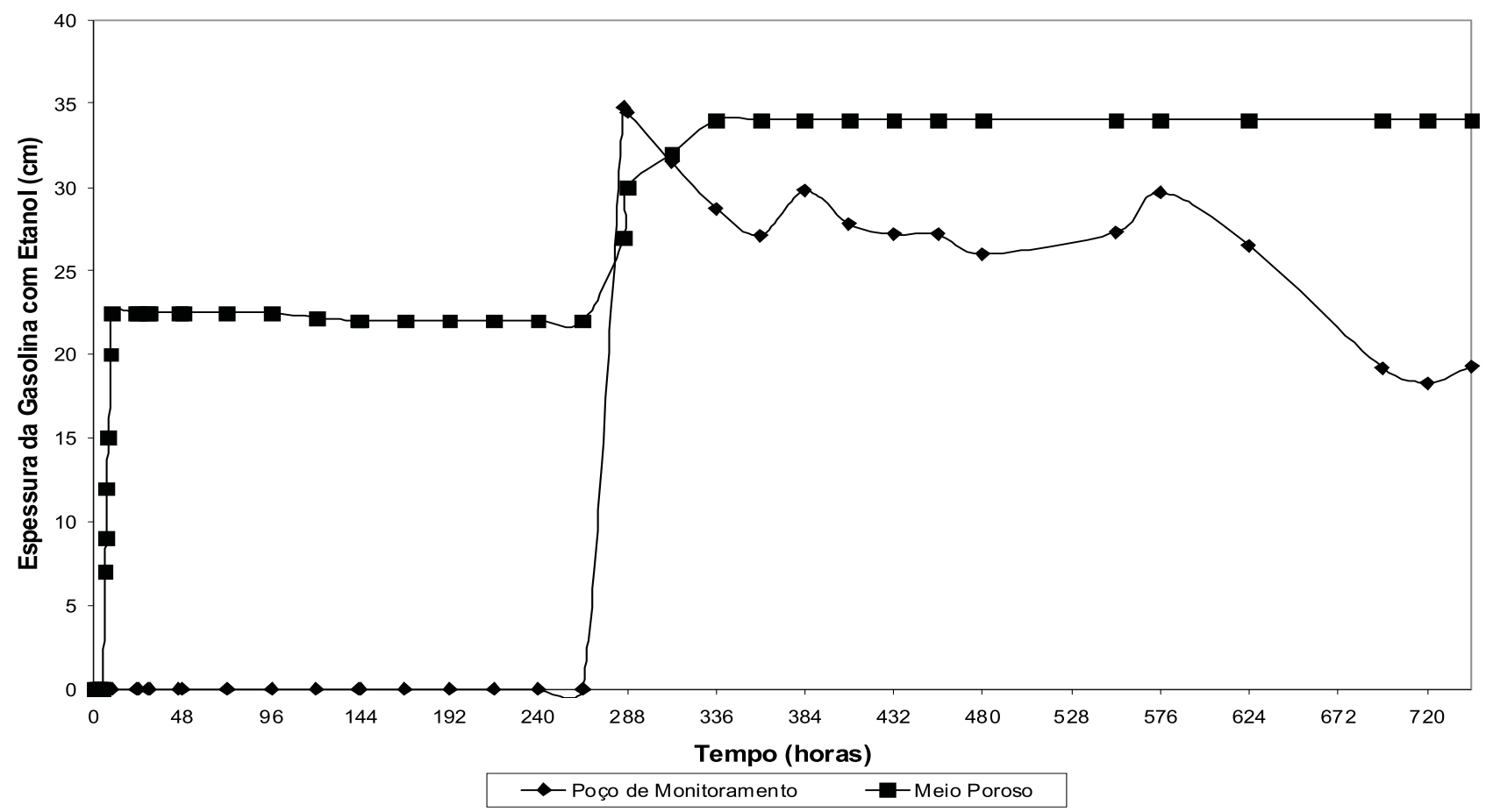

Gráfico 2. Variação da espessura da gasolina com etanol no meio poroso e no poço de monitoramento. 


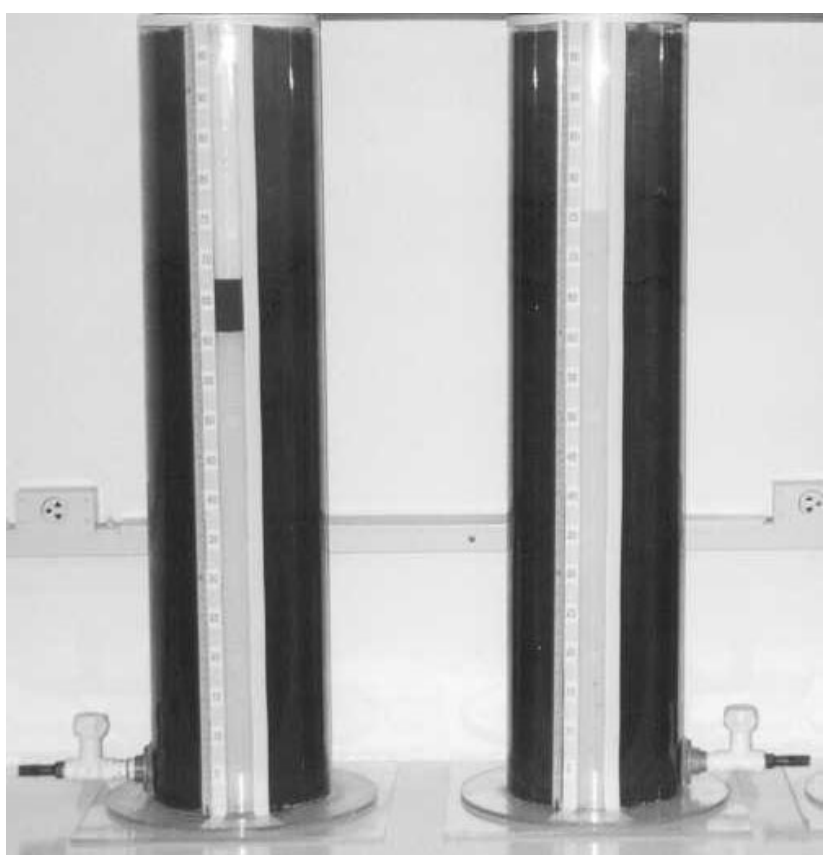

Foto 3. Tempo: 6 horas e 30 minutos. Coluna 1 (esquerda). Gasolina no poço de monitoramento: $5,7 \mathrm{~cm}$. Coluna 2 (direita). Nível d'água: 75,50 cm.

Em uma situação real, mantendo-se o comportamento observado no experimento, após o vazamento de um tanque subterrâneo contendo gasolina com etanol (20 a 24\%), a gasolina irá aparecer em um poço de monitoramento dentro da pluma de contaminação somente depois que uma boa parte do etanol existente em sua composição tiver sido eliminada, através do particionamento para a água subterrânea, e ter deixado no caminho de sua migração massa suficiente de gasolina para que a mesma possa migrar para o poço de monitoramento.

O Gráfico 3 mostra a relação direta existente entre o aumento da concentração de BTX, com o aumento da concentração de etanol, evidenciando o efeito co-solvente do mesmo, aumentando a solubilidade dos compostos orgânicos não polares, como BTX.

A Figura 5 mostra esquematicamente a migração da E-20 no meio poroso até atingir o poço de monitoramento, assumindo fluxo radial a partir do centro do tubo de vidro. A Figura 5A mostra que após a E-20 entrar em contato com a água da franja capilar houve a formação da fase aquosa e da fase gasolina.

A Figura 5B mostra a evolução da migração da fase aquosa espalhando-se lateralmente, alcançando os limites da coluna na Figura 5C.

O deslocamento da água pela E-20 seguiu a curva de drenagem, sendo o fluido molhante (água) drenado dos

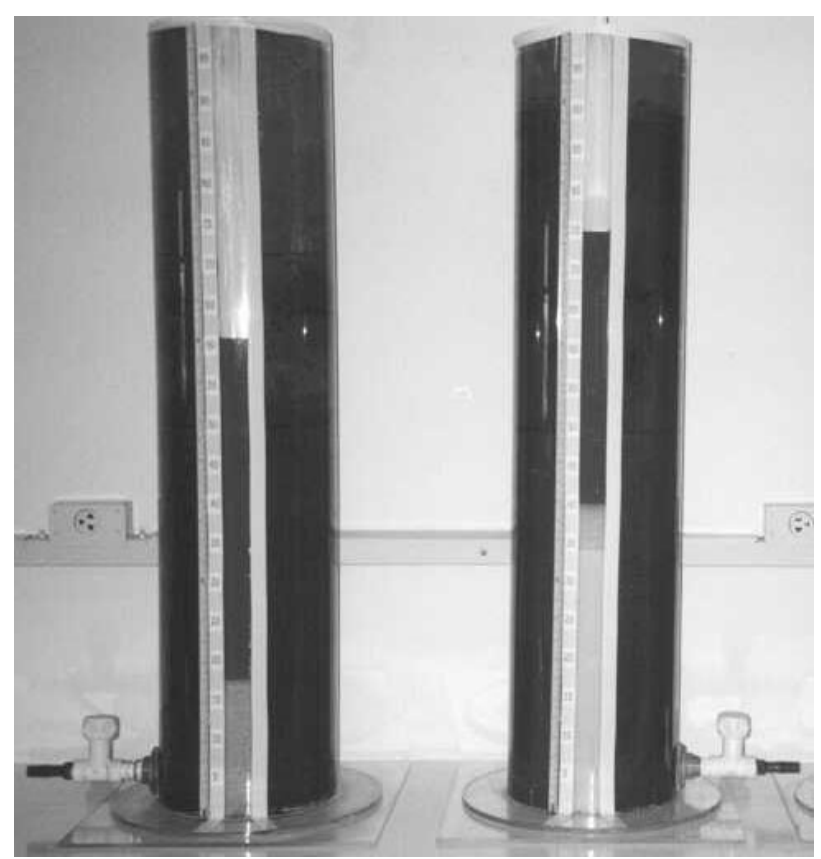

Foto 4. Tempo: 286 horas. Coluna 1 (esquerda). Gasolina no poço de monitoramento: 44,10 cm. Coluna 2 (direita). Gasolina no poço de monitoramento: $34,80 \mathrm{~cm}$.

poros maiores primeiro pelo fluido não molhante (gasolina). Nesse percurso, ocorre uma redução no volume da E-20, devido ao particionamento para a água, além de uma redução no volume da água presa nos poros, passando a formar a fase aquosa formada por etanol e gasolina dissolvida.

Quando a E-20 migrou deslocando a água, houve a precipitação da fase gasolina nos poros na forma de glóbulos à medida que mais etanol era particionado para a água, carreando os compostos mais solúveis (BTX) da mesma, o que foi verificado através do aumento progressivo de sua concentração na água. Tanto a fase aquosa quanto a fase gasolina começou a migrar por caminhos preferenciais, alterando a permeabilidade do meio poroso, fazendo com que, além do espalhamento lateral, houvesse também uma migração vertical verificada pelo aumento crescente da espessura de fase aquosa nos limites da coluna (Figura 5D).

Embora não fosse possível verificar visualmente no meio poroso, quando a fase gasolina conseguiu migrar até o limite do poço de monitoramento (Figura 5E), a mesma penetrou no poço formando a espessura aparente de fase livre dentro do mesmo.

Logo em seguida, a fase gasolina atingiu os limites da coluna (Figura 5F) e então foi possível verificar visualmente que a mesma havia deprimido a franja capilar em 63\%, devido à redução da tensão interfacial em 67\%, causada pelo particionamento de etanol para a água. Essa relação inversa 


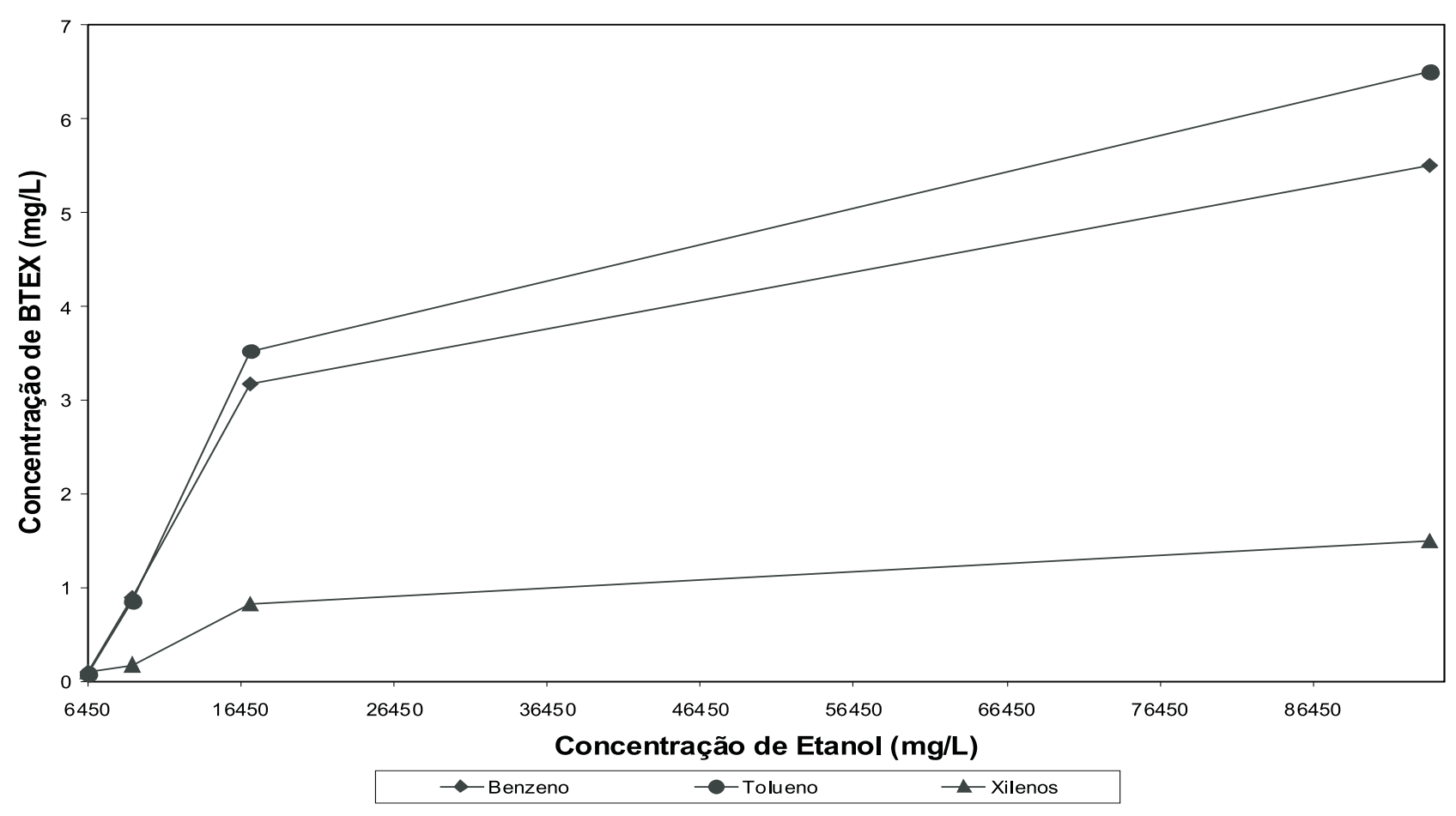

Gráfico 3. Efeito da co-solvência de etanol sobre a solubilidade de BTX da E-20.
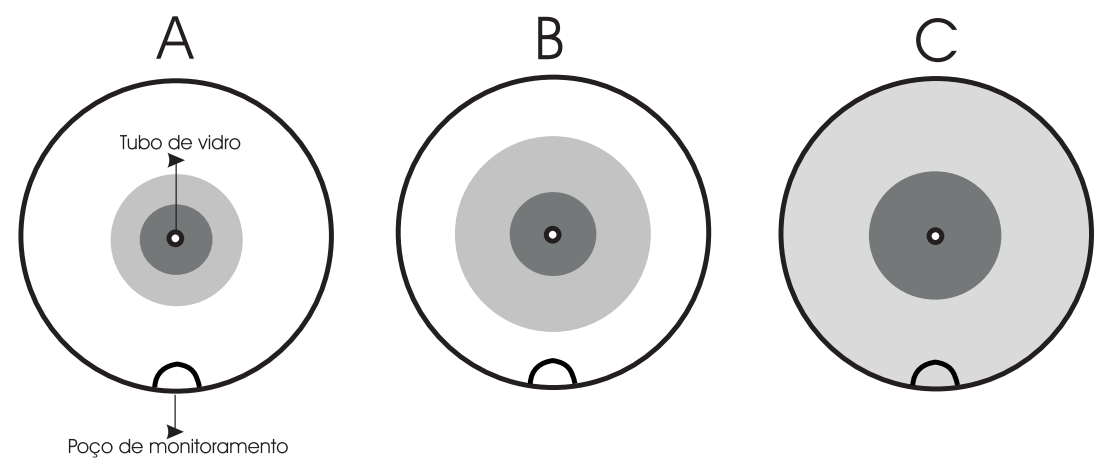

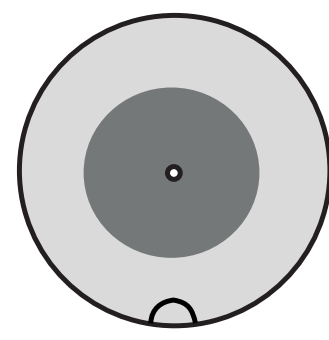

D

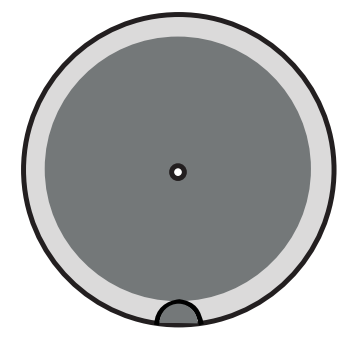

E

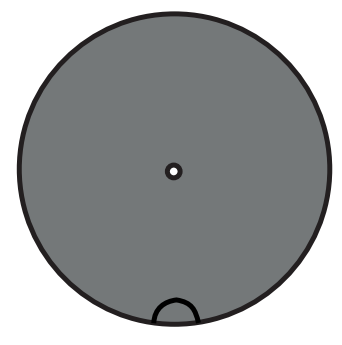

$\mathrm{F}$

Fase gasolina

Fase aquosa

Água

Figura 5. Esquema mostrando a migração da E-20 na Coluna 2. 
entre o aumento do conteúdo de etanol e a redução da tensão interfacial já foi constatada por vários autores, como Ryan e Dhir (1996), Oliveira (1997), Jawitz et al. (1998) e Powers et al. (2001).

Em uma situação real, mantendo-se o comportamento observado no experimento para a gasolina pura e para a E-20, pode-se afirmar que:

a. a E-20 levaria mais tempo para aparecer em um poço de monitoramento em relação à gasolina pura, levando-se em consideração que o tempo obtido neste experimento para que a E-20 penetrasse no poço de monitoramento foi 33 vezes maior.

b. o volume de E-20 necessário para formar uma massa suficiente de gasolina para penetrar no poço de monitoramento foi quatro vezes maior, pois a E-20 ocupa mais poros.

c. a fase residual formada durante a migração da E-20 poderia posteriormente, caso não fosse totalmente re-dissolvida, ser distribuída por grandes distâncias, gradiente abaixo da área fonte de contaminação, e gerar uma fonte de contaminação permanente.

d. as concentrações de BTX são significantemente mais altas em uma pluma de fase dissolvida de E-20, em relação a uma pluma de fase dissolvida de gasolina pura, apesar da fração molar de BTX ser menor na primeira, devido à adição de etanol em sua composição.

e. em uma situação real, além do etanol aumentar a transferência de massa de BTX para a água subterrânea, ele também seria responsável pelo aumento da pluma de BTX, pois a redução da tensão interfacial entre a E-20 e a fase aquosa potencializaria a capacidade de migração da mesma em relação à gasolina pura.

f. a redução da tensão interfacial contribuiu para a redução na altura da franja capilar, com o aumento do conteúdo de etanol aquoso.

\section{CONCLUSÕES}

1. a espessura aparente da gasolina pura foi 2,6 vezes superior à espessura real da fase livre e a espessura aparente da E-20 foi 0,6 vezes superior à espessura real da fase livre.

2. a tensão interfacial da E-20 foi $67 \%$ inferior à tensão interfacial da gasolina pura, possibilitando que uma quantidade maior de poros fosse acessada, refletindo em valores de saturação total, para a E-20, 54\% superior ao da gasolina pura.

3. parte da fase gasolina da E-20 pode ter sido depositada como glóbulos desconectados nos poros, caracterizando uma saturação residual, devido ao particionamento preferencial do etanol para a água subterrânea e o conseqüente enriquecimento em gasolina da fase gasolina. Esta saturação residual deve ter dificultado o fluxo e, conseqüente- mente, reduzido a permeabilidade relativa para a fase aquosa, causando o retardamento da chegada da E-20 no poço de monitoramento.

\section{REFERÊNCIAS BIBLIOGRÁFICAS}

ABDULA. S.; KIA, S. F.; GIBSON, T. L. Limitations of monitoring wells for the detection and quantification of petroleum products in soils and aquifers. Ground Water Monitoring Review, v. 9, n. 2, p. 90-99, 1989.

ABDUL, A. S. Migration of petroleum products through sandy hydrogeologic systems. Ground Water Monitoring Review, v. 8, n. 4, p. 73-81, 1988.

ADAMS, T. V.; HAMPTON, D. R. Effects of capillarity on DNAPL thickness in wells and in adjacent sands. In: WEYER, K. U. (Ed.). Surface contamination by immiscible fluids. Rotterdam: Balkema, 1992. p. 131-138.

BALLESTERO, T. P.; FIEDLER, F. R.; KINNER, N. E. An investigation of the relationship between actual and apparent gasoline thickness in a uniform sand aquifer. Ground Water, v. 32, n. 5, p. 708-718, 1994.

CETESB. Cetesb. Disponível em: www.cetesb.sp.gov.br. Acesso em: 07 jul. 2002.

CETESB. Prevenção e atendimento a vazamentos em postos de combustíveis. São Paulo: SMA/CETESB, 2001. 59 p. Apostila.

De PASTROVICK, T. L.; BARADAT, Y.; BARTHEL, R.; CHIARELLI, A.; FUSSELL, D. R. Protection of ground water from oil pollution. Hague, Netherlands: Cowcave, 1979.p. 1-61.

DURNFORD, D.; BROOKMAN, J.; BILLICA, J.; MILLIGAN, J. LNAPL distribution in a cohesionless soil: a field investigation and cryogenic sampler. Ground Water Monitoring Review, v. 11, n. 3, p. 115-122, 1991.

FARR, A. M.; HOUGHTALEN, R. J.; McWHORTER. Volume estimation of light nonaqueous phase liquids in porous media. Ground Water, v. 28, n. 1, p. 48-56, 1990.

FERREIRA, S. M. Relação entre a espessura real e aparente da gasolina com etanol e da gasolina pura em colunas de laboratório. 2003. 107 p. Tese (Doutorado) Instituto de Geociências, Universidade de São Paulo, São Paulo.

HALL, R. A.; BLAKE, S. B.; CHAMPLIN, S. C. Determination of hydrocarbon thickness in sediments using borehole data. In: NATIONAL SYMPOSIUM ON AQUIFER RESTORATIONAND GROUNDWATER MONITORING, 4., 1984, Columbus. Proceedings... Columbus, OH: National Water Well Association, 1984. p. 300-304.

HAMPTON, D. R.; MILLER, P. D. G. Laboratory investigation of the relationship between actual and apparent product thickness in sands. In: CONFERENCE ON PETROLEUM HYDROCARBONS AND ORGANIC CHEMI- 
CALS IN GROUND WATER - PREVENTION, DETECTION, AND RESTORATION, 1988, Dublin. Proceedings... Dublin, OH: National Ground Water Association, 1988. p. 157-181.

HUNTLEY, D.; HANK. R. N.; CORLEY, H. P. Nonaqueous phase hydrocarbon in a fine-grained sandstone: 1 . Comparison between measured and predicted saturations and mobility. Ground Water, v. 32, n. 4, p. 626-634, 1994.

KEMBLOWSKI, M. W.; CHIANG, C. Y. Hydrocarbon thickness flutuations in monitoring wells. Ground Water, v. 28 , n. 2, p. 244-252, 1990.

LAL, R.; BRIDGE, B. J.; COLLIS-GEORGE, N. The effect of column diameter on the infiltration behaviour of a swelling soil. Australian of Journal Soil Research, v. 8, p. 185-193, 1970.

LENHARD, R. J.; PARKER, J. C. Estimation of free hydrocarbon volume from fluid levels in monitoring wells. Ground Water, v. 28, n. 1, p. 57-66, 1990.

OLIVEIRA, E.; BARKER, J.; BANKS, J. Efeitos da variação do nível d'água em fase livre de gasolina pura e de gasolina com etanol. In: CONGRESSO BRASILEIRO DE ÁGUAS SUBTERRÂNEAS, 10., São Paulo, 1998. Resumos... São Paulo: ABAS, 1998. p. 10.

OLIVEIRA, E. Ethanol flushing of gasoline residuals microscale and field scale experiments. 1997. Tese (Doutorado) - Universidade de Waterloo, Waterloo.

PEREIRA, M. A. C. Alteração da espessura da fase livre da gasolina sob ação co-solvente do etanol. 2000.85 p. Dissertação (Mestrado) - Instituto de Geociências, Universidade de São Paulo, São Paulo.

SCHIEGG, H. O.; MCBRIDE, J. F. Laboratory setup to study two-dimensional multiphase flow in porous media. In. PETROLEUM HYDROCARBONS AND ORGANIC CHEMICALS IN GROUND WATER CONFERENCE, 1987, Houston. Proceedings... Houston: National Water Well Association, 1987. p. 371-385.

SCHIEGG, H. O. Considerations on water, oil, and air in porous media. Water Science and Technology, v. 17, p. 467-476, 1985.

SIMMONS, C. S.; McBRIDE, J. F.; CARY, J. W.; LENHARD, R. J. Organic liquid infiltration into unsaturated porous media. In: WEYER, K. U. Surface contamination by immiscible fluids. Rotterdam: Balkema, 1992. p. 213-219.

WADDILL, D. W.; PARKER, J. C. Recovery of light, nonaqueous phase liquid from porous media: laboratory experiments and model validation. Journal of Contaminant Hydrology, v. 27, p. 127-155, 1997.

WILSON, S. B.; BROWN, R. A. In situ bioreclamation: a cost-effective technology to remediate subsurface organic contamination. Ground Water Monitoring Review, v. 9, n. 1, p. 173-179, 1989. 